\title{
Analisis Teknologi Charger Untuk Kendaraan Listrik - Review
}

\author{
Firdaus Sutra Kamajaya, Muhammad Muzmi Ulya \\ Teknik Mesin Fakultas Teknik Universitas Brawijaya \\ Jalan MT. Haryono No. 167, Lowokwaru, Jawa Timur 65145 \\ E-mail: firdaussutra@yahoo.co.id
}

\begin{abstract}
Electric vehicles are a choice for the future. Therefore, the electric vehicle will be spreads in the community. The public is the average consumer who does not have knowledge about electric vehicles, especially for problem charger. Charger technology in an Electric Vehicle Supply Equipment (EVSE) consists of three types, namely AC level 1, AC level 2 and DC fast charging. Each type has advantages and disadvantages. The disadvantage of AC level 1 type is take a long time for charging (about 20 hours) and the advantage is no risk of damaging the battery. AC level 2 has shortcomings that are still relatively long time to process the charge but shorter process than the AC charge level 1 and there is no high risk of damaging to the battery. $D C$ fast charging has excesscharge process is very short (express)at range 20-30 minutes, but the disatvantage is very high risk of damaging the batteries in continuous usage. This paper also provide discussion for placement of any type of charger, so that people will understand.
\end{abstract}

Keywords: Charger, EVSE,AC level 1, AC level 2, DC fast Charging

\section{PENDAHULUAN}

Kendaraan listrik yang semula mulai menghilang kini mulai berkembangkembali. Bahkan mulai diminati oleh masyarakat awan. Electrical vehicles akan selalu berhubungan dengan listrik sebagaimana juga smartphone selalu berhubungan dengan listrik, oleh karena itu peralatan tersebut akan membutuhkan sistem untuk mengisi kembali kebutuhan listrik untuk pengoprasian. Karena jika tidak di isi ulang atau charging maka peralatan tidak berguna (useless).

Charging atau pengisian ulang sumber listrik yang umumnya berupa baterai litium ion atau nickle ion dan lainya menjadi hal utama dalam membangun sebuah sistem electrical vehicle. Karena menjadi sebuah komponen utama maka dari itu sangat pentinglah bagi kita untuk dapat memahami bagaimana proses charging agar dapat optimal dalam kinerjanya. Selain optimal juga bagaimana waktu yang dapat dihabiskan untuk men-charge sebuah kendaraan listrik.

Teknologi Electric Vehicle Supply Equipment (EVSE) memberikan energi listrik dari sumber listrik untuk mengisi baterai pada Plug-in Electric Vehicle (PEV) ini. EVSE berkomunikasi dengan PEV untuk memastikan bahwa aliranlistrik yang diisikan sudah tepat dan aman. Unit EVSE sering disebut sebagai stasiun pengisian. Komponen dasar dariteknologi EVSE adalah sebagai berikut:

EVSE [1]

EVSE adalah peralatan yang terhubun ke sumber daya listrik, dengan menyediakan arus bolak-balik(AC) atau arus searah (DC) . pemilihan kapasitas pengisian EVSE sangat penting karena EVSE memiliki pengaruh langsung pada seberapa cepat baterai dapat diisi ulang. Sebagai contoh, Level 2 EVSE tersedia dalam 20, 30 dan 40 ampere, semakin tinggi ampere maka proses pengisian ulang lebih cepat. Namun, charger onboard PEV ini harus memiliki kemampuan untuk mencocokkan output penuh dari EVSE untuk mewujudkan waktu tercepat dalam mengisi ulang.

\section{Electric Vehicle Connector [4]}

Electric Vehicle Connector adalah perangkat yang terhubung ke kabel EVSE yang menyediakan koneksi fisik antara EVSE dan PEV. Ada tiga konektor dominan digunakan saat ini,yaitu: konektor SAEJ1772 berdasarkan (dikembangkan oleh Amerika Serikat), konektor CHAdeMO (dikembangkan oleh Jepang), dan konektor Super charger (dikembangkan oleh Tesla yang digunakan 
secara eksklusif untuk pengisian mobil listrik Tesla).

\section{Electric Vehicle Inlet [1]}

Electric Vehicle Inleta dalah Perangkat pada kendaraan listrik yang menyediakan koneksi fisik antara PEV dan konektor EVSE. Beberapa jenis PEV memiliki lebih dari satu port inlet dan lokasi yang berbeda antara satu kendaraan dengan kendaraan lain.

\section{Battery Charger [3]}

Battery Charger adalah perangkat yang digunakan untuk mengisi atau mengganti muatan listrik pada baterai PEV. Waktu yang dibutuhkan untuk mengisi ulang baterai bergantung pada tegangan atau arus yang dihasilkan battery charger, jika arus atau tegangan terlalu rendah maka waktu charging akan membutuhkan waktu yang lama, sebaliknya jika tegangan atau arus tinggi maka waktu charging akan lebih singkat.

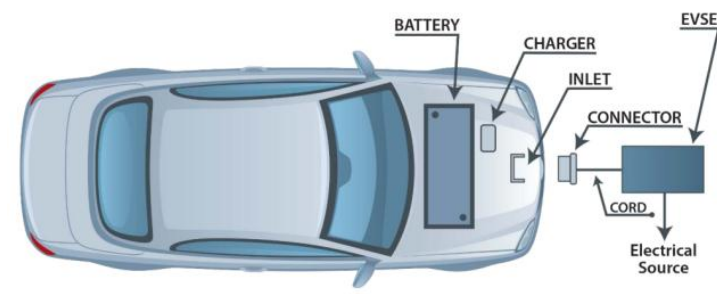

Gambar 1. Teknologi EVSE [1]

Klasifikasi Charger EVSE [5]

EVSE diklasifikasi menjadi AC level 1, AC level 2 dan DC Fast Charge (DCFC). Klasifikasi EVSE berkenaan dengan tingkat daya yang dihasilkan peralatan untuk mengisi ulang baterai PEV. Semakin tinggi level maka akan mengurangi waktu yang dibutuhkan untuk mengisi ulang baterai.
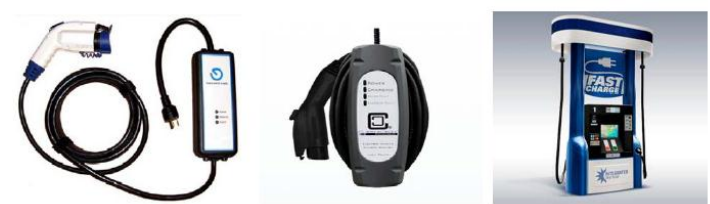

Gambar 2.Klasifikasi Charger [1]

AC Level 1 Charging

Pengisian level 1 menggunakan standard residensial 120-volt AC outlet, mengkonsumsi daya yang sama dengan toaster. Kebanyakan pabrikan PEV menentukan AC level 1 EVSE sebagai standard agar tidak perlu memakai perangkat tambahan. Pengisian ulang AC level 1 dapat menambah kuranglebih 4 mil perjalan per jam. Charging AC level 1 merupakan pengisian ulang baterai yang paling umum digunakan dan dapat mengisi ulang baterai PEV dalam waktu semalam, tetapi, jika baterai PEV habis seluruhnya bias memakan waktu sampai 20 jam untuk mengisi ulang.

\section{AC level 2 Charging}

Pengisian AC Level 2 menggunakan residensial 220-volt atau komersial 208-volt AC electrical service, konsumsi dayanya kurang lebih sama dengan pengering pakaian. Pengisian ulang level 2 dapat menambah kurang lebih 15 mil perjalanan untuk 1 jam pengisian pada kendaraan dengan $3.3 \mathrm{~kW}$ onboard charger, atau 30 mil untuk 1 jam pengisian pada kendaraan dengan $6.6 \mathrm{~kW}$ onboard charger. Perangkat level 2 EVSE didesain untuk pengisian ulang yang lebih cepat dan membutuhkan tetapi dalam instalasi listriknya dibutuhkan ahli dan juga menggunakan rangkaian listrik yang mumpuni. Baterai PEV level 2 yang habis seluruhnya memakan waktu selama 7 jam untuk mengisi ulang.

\section{Fast Charging (DCFC)}

Peralatan DCFC membutuhkan komersial 480-volt AC power service dan konsumsi dayanya kurang lebih sama dengan 15 pengatur suhu udara ukuran normal. Pengisian ulang DCFC dapat menambah kurang lebih 80-100 mil perjalanan dengan pengisian selama 20-30 menit. DCFC EVSE merubah AC menjadi DC didalam peralatan EVSE, memotong jalur charger mobil untuk menyediakan arus DC berkekuatan tinggi langsung menuju traction baterai PEV melewati inlet pengisian padakendaraan. Ada 2 standard untuk konektor yang digunakan pada DCFC, yaitu: SAE J1772 Combo (dikembangkan Amerika Serikat). Dan konektor CHAdeMO (dikembangkan Jepang). Dalam praktisnya, kedua konektor bekerja dengan sangat baik dan banyak (tidak semua) PEV yang bias menggunakan kedua konektor tersebut. DCFC dapat mengisi ulang baterai PEV yang habis seluruhnya dalam waktu kurang lebih 30 menit. 
Karena perannya yang penting maka kami menganalisa teknologi charging yang dapat diterapkan dalam masyarakat umum baik untuk penggunaan pribadi atau penggunaan umum seperti pada station for electrical vehicle yang sudah marak di bangun di luar negeri seperti Amerika, Jerman, Malaysia, Prancis dan sebagainya. Analisa ini bertujuan untuk mendapatkan data dari masing-masing teknologi agar kita dapat mengembangkan lebih lanjut, atau dapat mencegah jika terdapat ketidak sesuaian atau juga sebagai rujukan untuk pemilihan charger agar tidak merusak baterai kendaraan listrik milik kita.

\section{METODOLOGI PENELITIAN}

Metode penelitian yang digunakan adalah metode komparatif jenis charger. Beberapa indikasi yang ingin diteliti adalah lama charging, berapa daya listrik yang dibutuhkan. Dari data-data tersebut, dapat menentukan tempat-tempat dan situasi yang tepat dalam pemakaian setiap jenis charger serta efeknya terhadap baterai. Data - data yang digunakan berasal dari literatur-literatur penelitian sebelumnya.

\section{HASIL DAN PEMBAHASAN}

Tabel 1. Tabel Perbandingan Klasifikasi Tipe Charger

\begin{tabular}{|c|c|c|c|c|c|c|}
\hline Jenis Charger [2] & Waktu Charge [2] & Voltage/Amps[2] & Power Equivalent [2] & Instalasi [2] & Kelebihan [4] & Kekurangan [4] \\
\hline AC level 1 & 20 jam & $120 / 15$ & Toaster & Self & $\begin{array}{l}\text { Irit daya, tidak merusak baterai, } \\
\text { mudah digunakan secara pribadi }\end{array}$ & $\begin{array}{l}\text { Sangat lambat untuk mengisi } \\
\text { baterai }\end{array}$ \\
\hline AC level 2 & $7 \mathrm{jam}$ & $240 / 40$ & Clothes dryer & Professional & $\begin{array}{l}\text { Lebih cepat proses charge-nya } \\
\text { dari AC level 1, lebih irit dari } \\
\text { DCFC, tidak merusak baterai }\end{array}$ & $\begin{array}{l}\text { masih termasuk lama untuk } \\
\text { pengisian baterai, lebih boros } \\
\text { listrik dibanding AC level } 1\end{array}$ \\
\hline DC Fast Charging & $20-30$ menit & $480 / 125$ & 12 central AC & Professional & $\begin{array}{l}\text { Mengisi baterai dengan sangat } \\
\text { cepat (express) }\end{array}$ & $\begin{array}{l}\text { cepat merusak baterai dalam } \\
\text { penggunaan yang terus-menerus }\end{array}$ \\
\hline
\end{tabular}

Berdasarkan tabel, terlihat bahwa 240volt/40ampere, DC Fast Charge (DCFC) waktu proses charge antar tipe charger 480volt/125ampere.

berbeda-beda. Dengan urutan tipe charger AC level 1 membutuhkan waktu hinggai 20 jam sampai terisi penuh, AC level 2 membutuhkan waktu 7 jam, dan DC Fast Charging (DCFC) membutuhkan waktu 30 menit.

Waktu proses charge lebih cepat disebabkan oleh daya yang dihasilkan lebih besar, namun dengan hasil daya yang lebih besar maka konsumsi listrik lebih besar pula, charger tipe AC level 1 membutuhkan daya yang setara dengan toaster yaitu sekitar $600-$ $800 \mathrm{~W}, \mathrm{AC}$ level 2 membutuhkan daya yang setara pengering pakaian yaitu berkisar antara 1600-2000 W, sementara DC Fast Charging (DCFC) membutuhkan daya yang paling besar yaitu setaradengan 15 central AC atau sekitar $10500-14000$ W..

Setiap level charger juga menggunakan outlet plug yang berbeda-beda, setiap nilai plug menandakan berapa tegangan listrik yang bias dialirkan, untuk AC level 1 dapat mengalirkan 120volt/15ampere, AC level 2
Besarnya daya, voltase dan arus atau disebut juga lama waktu pengisian juga mempengaruhi umur baterai, semakin cepat waktu pengisian maka semakin menurun kapasitas baterai dari kapasitas awalnya. Hal ini dikarenakan besarnya daya, voltase dan arus mempengaruhi elektroda baterai secara negatif, maka dari itu pengisian dengan tipe $D C$ Fast Charging (DCFC) yang terlalu sering dapat memperpendek umur baterai, karena pengisiannya yang sangat cepat, yaitu sekitar $20-30$ menit, mengalirkan tegangan 480 Volt dan arus 125Ampere, pengisian menggunakan $D C$ Fast Charging (DCFC) lebih baik digunakan disaat genting seperti pada perjalanan jauh dan biasa di gunakan di station pengisian ulang baterai.

Pengisian menggunakan tipe AC level 1 sangat lama yaitu biasa sampai 20 jam, ini dikarenakan tegangan yang dapat dialirkan kecil yaitu 120 Volt dengan arus 15Ampere, maka charger Tipe AC level 1 tidak akan berakibat besar merusak kapasitas baterai. 
Tipe AC level 1 sebaiknya digunakan secara pribadi dengan intensitas pemakaian kendaraan listrik yang tidak terlalu intens dikarenakan waktu proses charge yang hamper satuhari.

Tipe AC level 2 dapat mengalirkan tegangan 240 volt dengan arus 40 ampere dimana akan membutuhkan waktu 7 jam untuk mengisi penuh baterai, menjadikanAC level 2 sebagai jawaban terbaik untuk menangani kekurangan dari AC level 1 dan DCFC karena waktu pengecasan yang relative tidak terlalu lama dan tidak terlalu cepat. Sehingga AC level 2 tidak beresiko tinggi merusak kapasitas baterai dan menjaga masa pakai baterai. Tempat yang baik untuk penempatan tipe $A C$ level 2 adalah di Perkantoran, tempat perbelanjaan, hotel, tempat penyewaan, tempat bermain golf juga penggunaan pribadi, karena waktu pengisiannya kurang dari setengah hari dan pada umumnya kendaraan listrik mampu bertahan dalam pemakaian penuh 12 jam tergantung dari tipe baterainya.

\section{KESIMPULAN}

Dari Pembahasan diatas dapat disimpulkan bahwa DCFC paling cepat dalam proses charge namun penggunaan yang secara kontinu dapat beresiko kerusakan pada baterai mobil listrik.Charger tipe inisangat cocok digunakan pada suatu stasiun pengisian baterai kendaraan listrik. Tipe charger AC level 2 merupakan opsi diantara DCFR dan AC level 1 , dengan waktu proses charger relatif lebih cepat dan tidak terlalu berdampak buruk pada baterai. Tipe ini cocok untuk pemakaian sehari-hari. Tipe charger AC level 1 dapat disimpulkan terburuk dalam waktu proses charge namun tipe ini merupakan opsi terbaik untuk memperpanjang umur baterai pemilik kendaraan listrik. Tipe ini hanya cocok digunakan untuk pribadi dimana pemakaian kendaraan listrik tidak terlalu intens.

\section{DAFTAR PUSTAKA}

[1] Doug Kettles, Februari2015, Electric Vehicle Charging Technology Analysis and Standards, Florida Solar Energy Center, AmerikaSerikat.

[2] The Massachusetts Department of Energy Recources, Juni 2014, Installation Guide For Electric Vehicle Supply Equipment (EVSE), The Massachusetts Department of Energy Recources, AmerikaSerikat

[3] Amtex Electronics, Februari 2012, Battery Charging Terminology, Amtex Electronics PTY LTD, Australia.

[4] Charles Botsford, Mei 2009, Fast Charging vs. Slow Charging: Pros and cons for the New Age of Electric Vehicles, AeroVironmentInc, Norwegia.

[5] U.S. Department of Energy, April 2012, Plug-In Electric Vehicle Handbook, U.S. Department of Energy, AmerikaSerikat. 